\title{
Layout Analysis and Planning Strategy of Market in Central Area of Big Cities from the Perspective of "Urban People"-Take Wuhan as an Example
}

\author{
Wei Wei, Xin Wang* \\ China Institute of Development Strategy and Planning, Wuhan University, No. 129 Luoyu road, Hongshan district, Wuhan, Hubei \\ province, China.
}

\begin{abstract}
How to cite this paper: Wei Wei, Xin Wang. (2021) Layout Analysis and Planning Strategy of Market in Central Area of Big Cities from the Perspective of "Urban People"-Take Wuhan as an Example. Journal of Humanities, Arts and Social Science, 5(2), 269-274.

DOI: 10.26855/jhass.2021.07.011
\end{abstract}

Received: September 25, 2021

Accepted: October 21, 2021

Published: November 9, 2021

*Corresponding author: Xin Wang, Business School, China Institute of Development Strategy and Planning, Wuhan University, No. 129 Luoyu road, Hongshan district, Wuhan, Hubei province, China.

Email: 413640101@qq.com

\begin{abstract}
Based on the analysis method of \&quot; City Man\&quot theory, this paper constructs the method system of seeking consensus match and planning layout of vegetable market based on the balance of rationality and materiality, taking the central city of Wuhan as an example, by using the methods of spatial data mining, Gis Network analysis, social investigation, regression analysis and so on, this paper identifies the difference and consensus of the demand and supply sides in their pursuit of the space contact opportunity, finds the balance point among them, and then takes the balance point as the goal, through the comparison of typical communities, this paper extracts the human settlement factors, such as population density, road property, land use property, and facility quality, which have significant influence on the satisfaction of vegetable market, and puts forward the planning and layout strategy of vegetable market.
\end{abstract}

\section{Keywords}

Wuhan, Vegetable market, Satisfaction, Urban People

\section{Introduction}

The vegetable market is one of the important components of supporting the construction of community public service facilities, serving the daily life of residents in the surrounding communities. As the key link of agricultural products circulation chain, the vegetable market is not only the agricultural products sales terminal connecting agricultural areas and urban areas, but also the agricultural products purchase front end connecting urban public commercial services and basic units (families), bearing the traditional market culture and fresh citizens' life(Lin, 2020). As the carrier of social space, the vegetable market provides residents with a platform for community communication on the basis of its specific functions, which allows people to break the closed environment of small families in modern society, integrate into the "face-to-face community" ( $\mathrm{Li}$ et al., 2017), and build a community behavior network with close contact among residents, which has become a key link in community life.

Although the supporting standards of public buildings have been adjusted according to the changes of demand content and supply mechanism, the guiding ideology and essential methods of allocation (such as the index of thousands of people) have remained basically unchanged (Huang et al., 2014), and the diverse needs brought about by the diversity of community members are often ignored (Chang \& Zhen, 2017). In this paper, the traditional community is divided into "15-minute living circle" (Chang \& Zhen, 2017) by using the theory of urban people, to identify the spatial contact opportunities of different types of urban people, to match with different types of human settlements, to rationally consider the location of the vegetable market and explore the rational spatial layout of the vegetable market from the consensus of 
"users" and "service partners", and to extract the satisfaction of population density, the proportion of public roads, the nature of land use and the quality of facilities through the comparison of typical communities.

\section{Theory and Method Construction}

"homo-urbanicus" is a "person who rationally chooses to inhabit and pursue the opportunity of space contact" (Liang, 2012). Through the identification of typical urban people and typical human settlements, the demand and supply are identified by consensus and matched by planning, so as to achieve the goal of optimization and upgrading. According to the planning paradigm of "urban man" theory, planning research can be divided into the following four steps:

(1) Determine the spatial contact opportunities and urban human factors: the spatial contact opportunities between the vegetable market and residents can be summarized as "accessibility of the vegetable market", "the number of residents covered by the vegetable market service" and "service level of the vegetable market"; The elements of "urban people" can be divided into vegetable market users and vegetable market service providers. The attributes of users can be divided according to the "age, gender and life stage" of residents, and the attributes of service providers can be divided according to the "scale and service radius" of the supporting vegetable market;

(2) Investigation and analysis of demand and supply: to investigate the current accessibility (quantified as distance), current accessibility satisfaction (percentage) and ideal accessibility based on self-existence/coexistence of market users; In the same way, investigate the status quo accessibility, status quo accessibility satisfaction and ideal accessibility based on self-existence/coexistence of market service providers;

(3) Consensus discrimination: identify the gap between market users and service providers based on the ideal value of self-existence/coexistence, select a reasonable ideal accessibility interval, and reach a consensus under the balance of self-existence/coexistence as the ideal accessibility result;

(4) Extraction of human settlement elements: with the goal of improving satisfaction and reaching the ideal accessibility consensus under the balance of self-existence/coexistence, the design principles, index system and management system in urban planning are used to change the variables of "typical human settlements" and improve the matching degree between "urban people" and "human settlements".

\section{Empirical Analysis}

\subsection{Analysis of the Overall Situation of the Community Vegetable Market}

The data acquisition scope of this study is defined in the central city of Wuhan, with a total area of about $695.71 \mathrm{~km}^{2}$. According to Wuhan's "15-minute living circle" delimitation and spatial optimization method (Wei \&Shep, 2019), the main city of Wuhan is divided into 489 living circles. In this paper, based on the years of vegetable market construction, 18 typical communities including new community, old community and old-new blending community are selected for analysis, and the relationship between user satisfaction and accessibility of vegetable market in the life circle composed of different communities is studied. In order to investigate the accessibility and satisfaction of "demanders" and "service providers" to the vegetable markets in the above areas, the author conducted questionnaire survey and interviews with the residents of the above 18 typical communities (urban people 1) from October 2018 to April 2019, and adopted the combination of online questionnaire agencies and field questionnaires, and obtained 1,800 valid questionnaires.

The survey results show that $75 \%$ of community residents use the vegetable market at least once in January, and $64.47 \%$ of them tend to go to the vegetable market once a day, once every half week and once a week for purchasing (Figure 1). As an important part of community public service facilities, the vegetable market is irreplaceable and closely related to the daily life of most families.

In terms of age, the population aged 20-40 has the highest proportion, followed by the population aged 41-60, followed by the population aged over 60 , and the population aged under 20 has the lowest proportion, which shows that the services provided by the vegetable market basically cover all age groups except children and teenagers. In terms of life stage (family structure), nuclear families accounted for $29 \%$ of the surveyed population, families living alone accounted for $14 \%$, main families accounted for $14 \%$, and insensitive families accounted for $43 \%$. This shows that the core families and the main families enjoy the service of the vegetable market. Considering the age and life stage, the age and life stage of the surveyed population are closely related (Figure 2).

\subsection{Accessibility Analysis}

It is the main entry point for the evaluation of vegetable market to study the difference between space equity, supply and demand through accessibility evaluation. Using GIS to analyze the service areas of 18 typical communities (Figure 3), the 5-minute, 10-minute and 15-minute accessibility maps of typical community vegetable markets were obtained. Be- 
cause the vegetable market in the old community was built a long time ago and there are a certain number of centralized farmers' markets, it is convenient for residents to purchase and travel, and the accessibility of the vegetable market in 15 minutes is over $90 \%$. There are differences in the 15 -minute accessibility of the new community vegetable market. The 15-minute accessibility of Baibuting and Fudi East Lake international community markets in the new and old blending communities is lower than $50 \%$. There are certain-scale fresh supermarkets and standard markets in Baibuting community. Due to the wide service range of large-scale markets, the average purchase travel time of residents is longer.

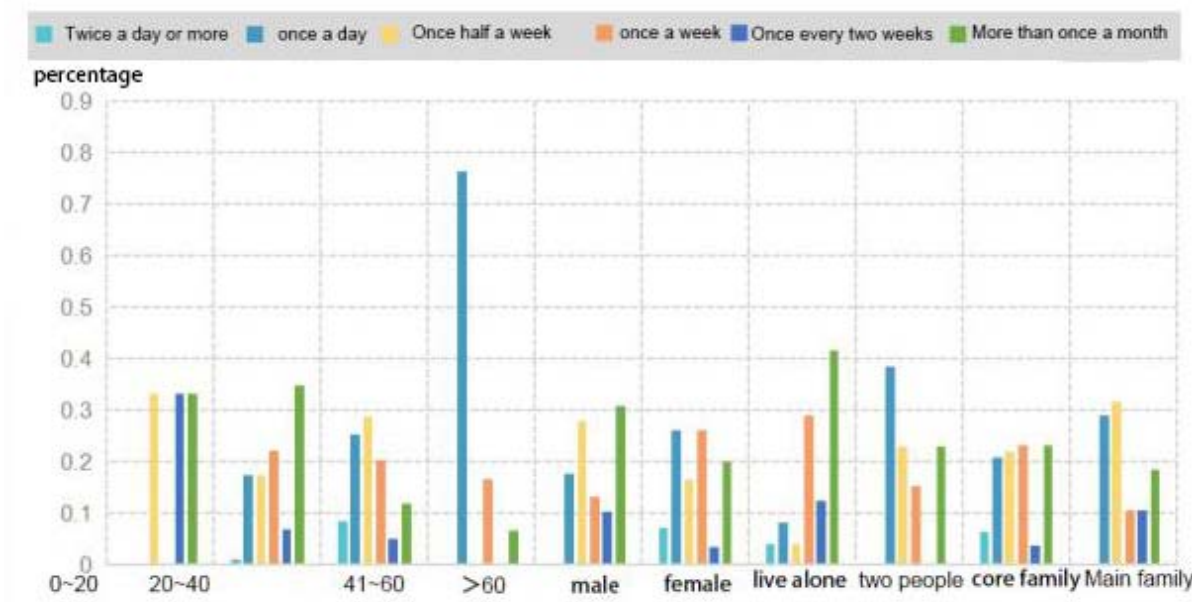

Figure 1. Frequency of use of residential vegetable markets.
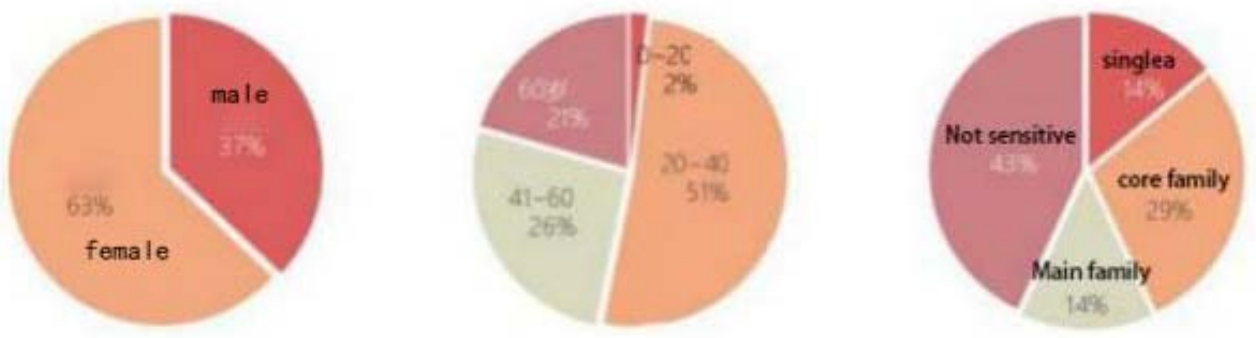

Figure 2. Gender, age and life stage of community residents.

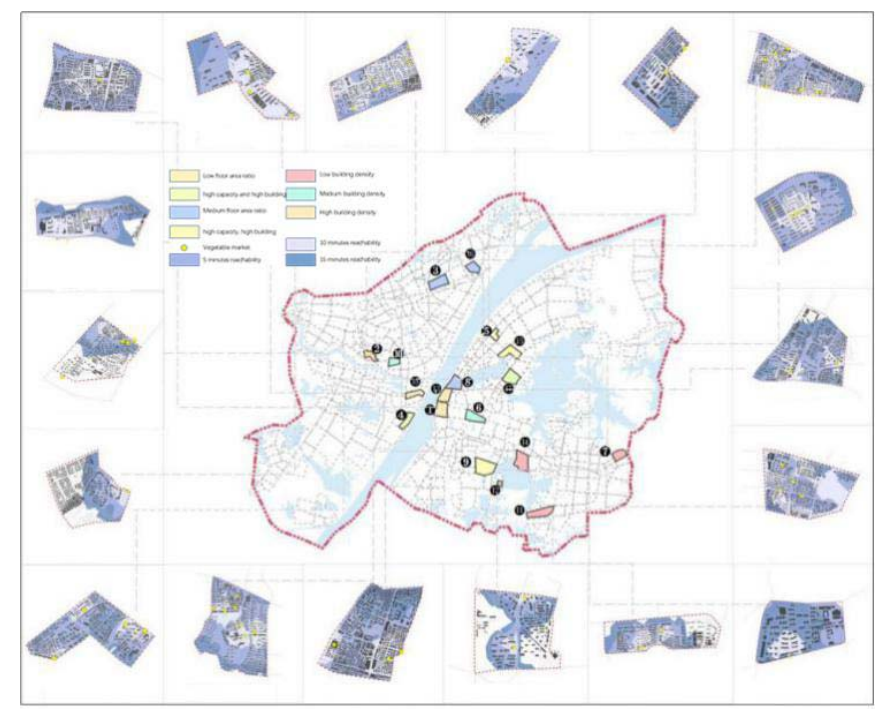

Figure 3. Accessibility analysis of typical community vegetable market. 
By means of questionnaire, the time taken by community residents with different attributes to reach the vegetable market on a daily basis was obtained. Overall $85.53 \%$ of the community residents could reach the vegetable market within 15 minutes. According to gender, 60.3\% of male residents can reach the market within 10 minutes, while $63.1 \%$ of female residents can reach the market within 10 minutes. Gender factors have no obvious tendency to reach the market within 15 minutes. According to age, the youth group is evenly distributed in each time period, and $72.09 \%$ of the residents in the middle-aged group can reach the vegetable market within 10 minutes, which has a strong tendency compared with the youth group and the old group. $91.23 \%$ of the residents in the old group can reach the vegetable market within 15 minutes, and are insensitive to the accessibility of the vegetable market within 10 minutes. According to the family structure, the residents living alone are evenly distributed in each time period, 92.31\% of the residents in the two-person world family can reach the vegetable market within 10 minutes, the nuclear families are evenly distributed in each time period without obvious tendency, and $68.42 \%$ of the residents in the main families can reach the vegetable market within 10 minutes. Based on the above analysis, the middle-aged population and two-person families are sensitive to the accessibility of the 15-minute vegetable market (Figure 4).

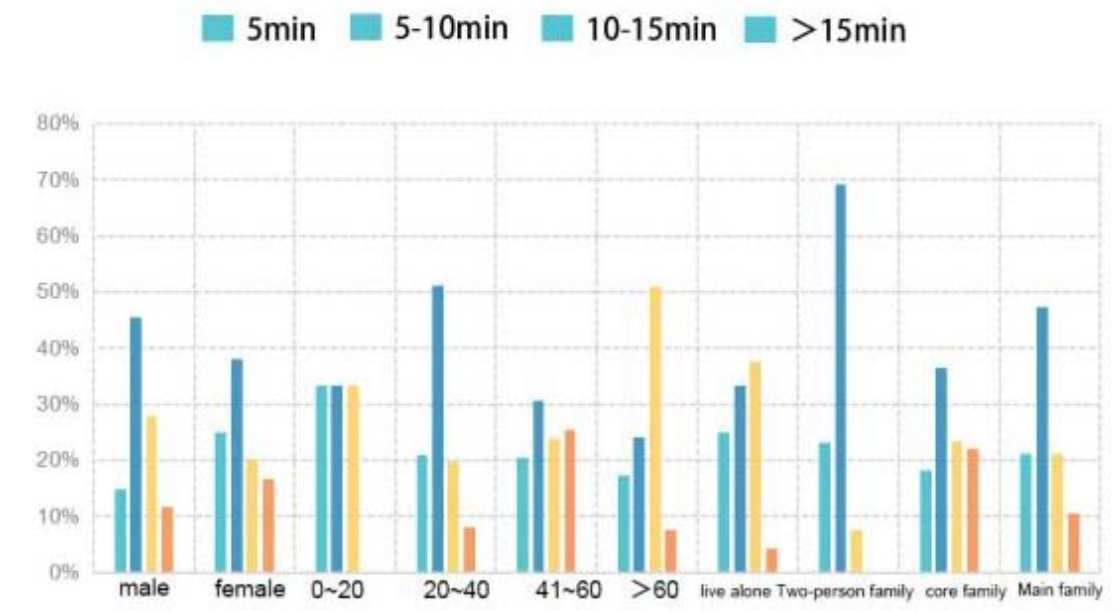

Figure 4. The time when residents arrive at the community vegetable market.

\subsection{Consensus Analysis of Demand Side}

The satisfaction evaluation of the vegetable market from the perspective of urban people is based on its rationality and physical properties, which is reflected in the accessibility of space contact opportunities. On the one hand, the delineation of the service radius of the vegetable market should take into account the residents' "self-existence psychology", that is, the community residents expect to reach the vegetable market conveniently and quickly, which is reflected in the distance required by the community residents; on the other hand, it also needs to meet the needs of market builders and service providers, which is reflected in the service radius of community market service providers. The intersection of the two is based on the service radius of "self-storage/coexistence".

\subsection{Traffic Distance Required by Community Residents}

In the actual investigation, residents' satisfaction with the vegetable market is mostly "relatively satisfied", and few residents choose "very satisfied". The questionnaire shows that the main factors affecting residents' consumption experience in the vegetable market are the environment and sanitation of the vegetable market, followed by the distance from the vegetable market. According to the survey statistics, the average satisfaction degree of community residents in each accessible distance is 74.56, and the relationship between satisfaction degree of vegetable market and accessible distance of community residents can be obtained by regression analysis. Figure 5 shows that when the coverage radius of the vegetable market is less than $1,000 \mathrm{~m}$, the walking distance is inversely proportional to the residents' satisfaction. It is worth noting that when the walking distance is within $200 \mathrm{~m}$, the residents' overall satisfaction is higher than 80 points, but the satisfaction increases slightly with the distance. When the vegetable market is too close to the residential area, the environmental problems caused by sewage discharge and noise pollution in the vegetable market may be the main reasons that affect the residents' satisfaction. When the walking distance of the vegetable market is $250 \mathrm{~m}$, the satisfaction of residents reaches its peak; when the walking distance is less than $350 \mathrm{~m}$, the satisfaction of residents is less than 80 points. By analyzing the satisfaction of the vegetable market at different accessible distances, it is found that when the walking 
distance is less than $600 \mathrm{~m}$, the residents' satisfaction decreases sharply with increasing distance, and when the distance exceeds $600 \mathrm{~m}$, the decreasing trend of residents' satisfaction is delayed, which indicates that when the walking distance is greater than $600 \mathrm{~m}$, the dominant factor affecting residents' satisfaction is no longer distance.

To sum up, when the walking distance of the vegetable market is more than $200 \mathrm{~m}$ and less than $350 \mathrm{~m}$, the residents' satisfaction is high, which can meet the residents" "self-saving” demand.

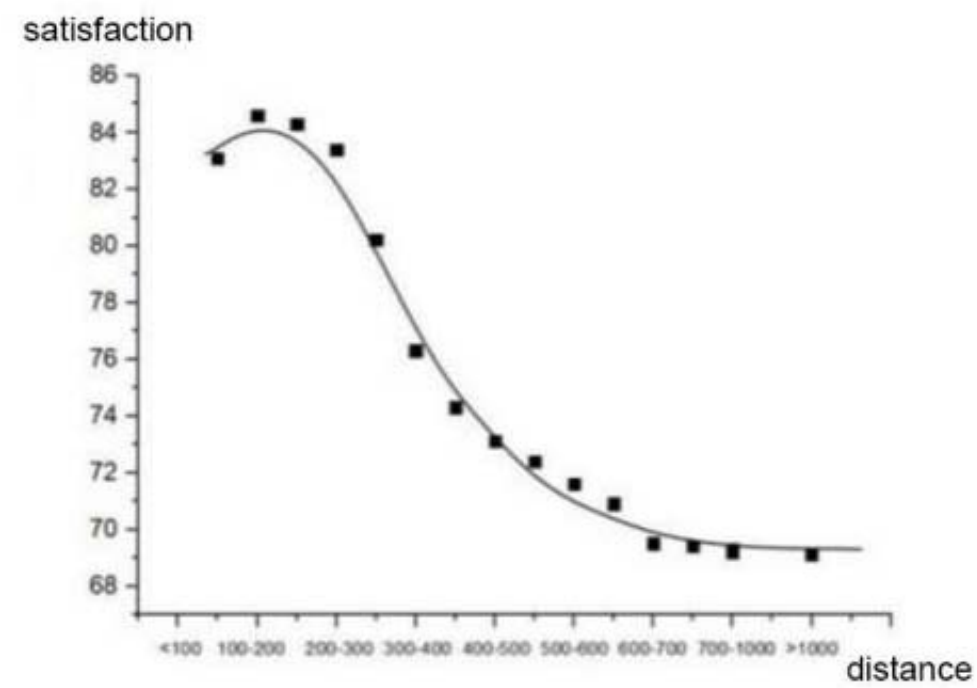

Figure 5. Satisfaction at different accessible distances in the vegetable market (\%).

\subsection{Demand Service Radius of Community Vegetable Market}

In the field investigation, 79 valid questionnaires were obtained from questionnaires distributed to vegetable market operators and sellers of agricultural and sideline products (urban people 2) in 18 typical living circles. The average values of "self-existing service radius" and "coexistence service radius" of vegetable market operators in each living circle were taken to analyze the service radius of vegetable market service providers based on self-existence and coexistence. The service radius of service providers in each living circle market is 125-205 meters based on self-existence and 367-452 meters based on co-existence (Figure 6). The results show that the service radius of market operators in living circles with large land area and poor comprehensive accessibility is larger based on self-existence and co-existence, while the service radius of market operators in living circles with dense facilities and uniform coverage of service areas is smaller. Average the expected service radius of vegetable market operators in typical life circle, and get that the expectation of vegetable market operators for the best service radius of vegetable market is $152-410 \mathrm{~m}$.

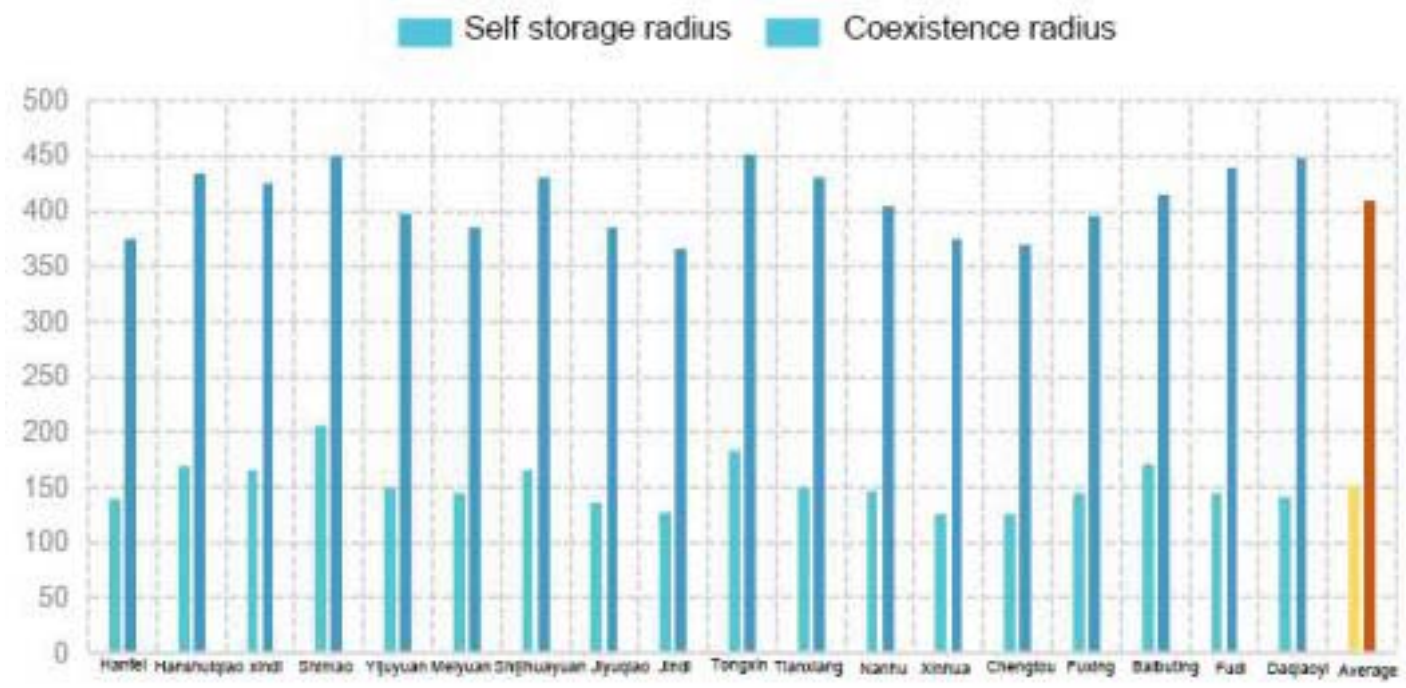

Figure 6. Reasonable service radius of vegetable market service provider. 


\subsection{Selection of the Best Service Radius}

In the previous paper, the ideal service radius interval of the two sides was studied from the satisfaction angle of the pursuers (community residents) and the providers (market operators). The selection of the ideal service radius of the vegetable market should meet the expectations of both the pursuers and the service providers, and meet the allocation standard of the commercial service building area of Wuhan vegetable market of $120 \mathrm{~m} / 1,000$ people. According to the above data analysis, the market operators' demand for the best service radius of the market is $152-410 \mathrm{~m}$, and the community residents' expectation for the best service radius of the market is $200-350 \mathrm{~m}$. The reasonable service radius is the intersection of the two, that is, the lower and upper limits of the community residents' ideal radius of the market. It is concluded that the reasonable service range of the pursuers and service providers is 200-350 m (Figure 7).

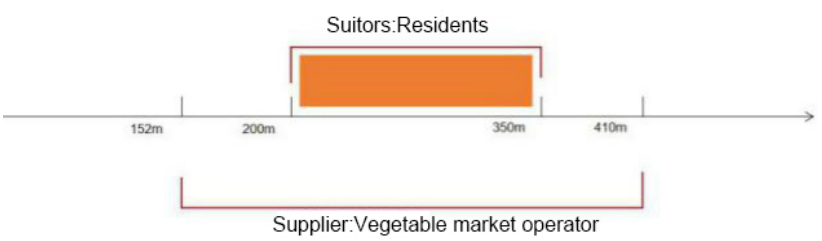

Figure 7. Division of service radius of vegetable market under the consensus of both parties.

\section{Planning Strategy}

Based on the above investigation and comparative analysis, we can improve the satisfaction of the vegetable market from three aspects: the basic attributes of human settlements, the attributes of roads, the nature of land use. In the aspect of density attribute, the population density of $1.3-47,000$ people/ $\mathrm{km}^{2}$ can be used as a variable index of living factors to improve the overall satisfaction of community life circle. In terms of road grade, urban expressways and main roads have larger traffic volume, faster speed and wider road width, which is inconvenient for pedestrians to walk back and forth, while urban secondary roads and branches can better gather popularity and facilitate people to walk and ride. Therefore, vegetable markets and fruit and vegetable shops should be arranged on both sides of urban secondary roads and branches with lower road grade. On the one hand, the nature of land use advocates the mixed use of multiple functions in a certain area to ensure that land use has multiple attributes to facilitate diversified community activities; on the other hand, the development scale should emphasize the scale requirements of the walking system to meet the accessibility requirements of the walking system.

\section{Research Conclusion}

On the basis of selecting "typical human settlements", starting from optimizing the location and layout of the vegetable market in the community living circle, according to spatial analysis, field investigation and questionnaire distribution of suppliers, this paper seeks the balance between the pursuers (community residents) and the providers (builders of public service facilities) of the vegetable market in the community living circle, summarizes the consensus interval of the service radius of the facilities, and expects to improve the satisfaction of the "typical city people" in terms of spatial contact opportunities.

\section{References}

Chang eun-yu and Zhen Feng. (2017). Practical reflection and social construction strategy of smart community—A case study of National Smart City in Jiangsu Province [J]. Modern City Studies.

Huang Meiyu, Zhou Suhong, Lin Kaixuan. (2014). An analysis of the implementation of the supporting structure of urban public construction in China during the transitional period. Modern City Studies.

Liu Bin. (2020). A study on the local ballet and the feeling of place in the city traditional vegetable market-Taking Qingyang district market in Chengdu as an example [J]. Urban issues.

Li Yixi, Zhang He, Feng Jian. (2017). Study on the locality and mechanism of the vegetable market in the Old City of Beijing [J]. Human geography.

Liang he-nian. (2012). C [J]. Urban planning.

Wei Wei, Hummingbird. (2019). Shep. 15-minute Life Circle Delineation and spatial optimization in Wuhan based on supply and demand matching, Wei Wei [J]. Planners. 